\title{
Co-composting of livestock manure with rice straw: Characterization and establishment of maturity evaluation system
}

Xiaoyong Qian ${ }^{\mathrm{a}, \mathrm{b}}$, Genxiang Shen ${ }^{\mathrm{b}}$, Zhenqi Wang ${ }^{\mathrm{b}}$, Chunxia Guo ${ }^{\mathrm{b}}$, Yangqing Liu ${ }^{\mathrm{b}}$,

Zhongfang Lei ${ }^{\mathrm{a}, *}$, Zhenya Zhang ${ }^{\mathrm{a}, *}$

${ }^{\text {a } G r a d u a t e}$ School of Life and Environmental Sciences, University of Tsukuba,

Tsukuba, Ibaraki 305-8572, Japan

b Shanghai Academy of Environmental Sciences, Shanghai 200233, China

*Corresponding author at: Graduate School of Life and Environmental Sciences, University of Tsukuba, Tsukuba, Ibaraki 305-8572, Japan. Tel/Fax: +81 298536703;

+81 298534712. Email address: lei.zhongfang.gu@u.tsukuba.ac.jp (Z. Lei);

zhang.zhenya.fu@u.tsukuba.ac.jp (Z. Zhang) 
Abstract: Composting is considered to be the primary treatment method for livestock manure and rice straw, and high degree of maturity is the principal requirement for safe land application of composting product. In this study pilot-scale experiments were carried out to characterize the co-composting of livestock manure and rice straw, as well as to establish a maturity evaluation index system for the composts obtained. Two pilot composting piles with different feedstocks were conducted for 3 months: (1) swine manure and rice straw (SM-RS); and (2) dairy manure and rice straw (DM-RS). During the composting process, parameters including temperature, moisture, $\mathrm{pH}$, total organic carbon (TOC), organic matter (OM), different forms of nitrogen (total, ammonia and nitrate), and humification index (humic acid and fulvic acid) were monitored in addition to germination index (GI), plant growth index (PGI) and Solvita maturity index. OM loss followed the first-order kinetics equation in both piles, and slightly higher OM mineralization rate was achieved in SM-RS pile. Also, SM-RS pile exhibited slightly better performance than DM-RS from the evolutions of temperature, OM degradation, GI and PGI. The C/N ratio, GI and PGI could be included in the maturity evaluation index system in which GI > 120\% and PGI >1.00 signal mature co-composts.

Keywords: Co-composting; swine manure; dairy manure; rice straw; maturity evaluation index system 


\section{Introduction}

Livestock breeding and rice production are the major agricultural industries in China. The annual amounts of fattening pigs and dairy cows exceed 0.6 billion and 0.1 billion (NBSC, 2011), resulting in an annual generation of nearly 0.3 billion tons of animal manure. The large quantity of animal manure is difficult to be completely utilized in a limited nearby arable land, and fresh animal manure is also not suitable for land application because of its containing pathogens, unstable nutrients and transportation cost issues (Hu et al., 2011). Serious environmental pollution has been triggered due to inappropriate manure disposal. According to the report on the first China Pollution Source Census issued by the Ministry of Environmental Protection in February, 2010, the annual chemical oxygen demand (COD) discharge from animal husbandry accounted for $40 \%$ of the total discharge amount from all the sources. Meanwhile, the sown area of paddy is about 30 million hectares (NBSC, 2011) with annual amount of 0.2 billion tons of rice straw being produced accordingly. Rice straw is mainly used for fuel (cooking and house heating), animal feed, fiber for pulping, and plowing into field. It has been reported that a very large proportion of rice straw was discarded or burned in the field due to lack of cost-effective treatment approaches, leading to severe water and air pollution (Wang et al., 2008). There is an urgent need to find appropriate methods for these wastes in order to reduce environmental pollution and recycle agricultural resources. Co-composting of livestock manure with rice straw can be one of the applicable resolutions ( $\mathrm{Li}$ et al., 2008), mostly due to the higher moisture and lower $\mathrm{C} / \mathrm{N}$ ratio of livestock manure 
while lower moisture and higher $\mathrm{C} / \mathrm{N}$ ratio of rice straw, especially in the areas where both two wastes are available.

Composting is a biological process in which organic matter (OM) can be utilized by aerobic thermophilic and mesophilic microorganisms as substrate and mainly converted into mineralized products $\left(\mathrm{CO}_{2}, \mathrm{H}_{2} \mathrm{O}, \mathrm{NH}_{4}{ }^{+}\right)$or stabilized $\mathrm{OM}$ (mostly as humic substances) (Bernal et al., 2009; He et al., 2009; de Guardia et al., 2010a; de Guardia et al., 2010b). Although composting has been widely practiced with its final products being used as fertilizer or soil amendment, there are still knowledge gaps in understanding it due to the high variety and heterogeneity of feedstocks (Li et al., 2008; Himanen and Hänninen, 2011). Besides, various composting systems add some difficulty in this understanding, probably resulting in the complexity of compost maturity evaluation system (Gao et al., 2010). Bernal et al. (2009) and Nolan et al. (2011) pointed out that compost maturity couldn’t be well described by a single property or parameter. In China, the standards for composts lay stress on the physical and chemical parameters like $\mathrm{pH}$, moisture, total nitrogen (TN) and OM without biological or agronomical parameters being considered, resulting in a less comprehensive and systematical assessment with respect to the maturity of composts and a potential risk of land application of unstable and immature composts (Gao et al., 2010). The principal requirement of a compost for it to be safely used in agricultural soil is a high degree of maturity of stability (Bernal et al., 2009). Some attempts have been tried on testing the effects of different feedstocks on process performance (Prades et al., 2000; Zhu, 2007; Li et al., 2008; Himanen and Hännien, 2011), and on 
evaluating compost maturity by using different parameters (Grube et al., 2006; Ko et al., 2008; Gómez-Brandón et al., 2008). Up to now, for the co-composting of the two main livestock manures and rice straw, still, little information can be found when these two aspects (i.e., physical/chemical and biological/agronomical parameters) are taken into consideration simultaneously, thus no maturity evaluation index system with agronomical parameters included is available. In addition, the relationship between the physical/chemical properties and biological/agronomical parameters is also scarce for the co-composting of the two main livestock manures and rice straw.

The objective of present study is to characterize the co-composting processes of swine/dairy manure and rice straw using different parameters including $\mathrm{pH}$, temperature, total organic carbon (TOC), different forms of nitrogen, OM, humus, germination index (GI) and plant growth index (PGI). A compost maturity evaluation index system is proposed and established to reveal the composting progress and the compost maturity. The relationship between the physical/chemical and biological/agronomical parameters are also discussed.

\section{Materials and methods}

\subsection{Experimental procedure}

Two pilot piles of composting were prepared with rice straw (RS) and two different livestock manures, namely swine manure (SM) and dairy manure (DM), respectively. The SM was collected from a swine farm in Pudong District, Shanghai, China with a productivity of 8,000 heads per year; the DM was from a dairy farm 
located in Jinshan District, Shanghai, China with 5,000 milk cows; and the RS was sampled from a paddy field in Qingpu District, Shanghai, China. Table 1 lists the main characteristics of the raw materials used in this study. In order to start the composting at desirable $\mathrm{C} / \mathrm{N}$ ratios, the feedstock mixtures were prepared in the following proportions on fresh weight basis (w.m.): $60 \% \mathrm{SW}+40 \% \mathrm{RS}$ for SM-RS pile and 67\% DM + 33\% RS for DM-RS pile, corresponding to theoretical C/N ratios between 35 and 40 .

Besides fresh manure and rice straw, two types of commercial composts were obtained from a local market for the maturity test: (1) Commercial compost A, provided by Shanghai Yunong Composting Plant, a product from co-composting of swine manure and rice straw; and (2) Commercial compost B, provided by Shanghai Lianye Composting Plant, a product from composting of dairy manure and rice straw.

Both piles weighted about $50 \mathrm{~kg}$ and each pile was conducted in quintuplicate. After being mixed completely, the feedstocks were put into foam boxes $(50 \times 50$ $\times 50 \mathrm{~cm}^{3}$ ) which were then placed in a climate chamber. The chamber was controlled at temperature of $30 \pm 1{ }^{\circ} \mathrm{C}$ and humidity of $70 \pm 5 \%$, respectively. During the composting process, the pile was manually mixed every $10 \mathrm{~d}$ and sampled every $15 \mathrm{~d}$ or $30 \mathrm{~d}$ for the determination of the designed parameters. The compost sample was obtained by mixing 5 sub-samples from 5 random sites of the pile at the same time.

\subsection{Analytical methods}


The core temperature was measured by a thermometer (ZDR-21, Hanghou Zeda Equipment Co, Ltd., China ) equipped in each feedstock at the depth of $25 \mathrm{~cm}$, and monitored every $24 \mathrm{~h}$. The $\mathrm{pH}$ of the raw material or compost sample was detected by a pH meter (SenION1 portable pH meter, $\mathrm{HACH}, \mathrm{USA})$ in a 1:5 (w/v) water-soluble extract. The moisture content and dry matter of the sample was obtained by drying at $105{ }^{\circ} \mathrm{C}$ in an oven for $12 \mathrm{~h}$, and the organic matter (OM) was determined by the weight loss after ignition at $430^{\circ} \mathrm{C}$ for $24 \mathrm{~h}$ (Navarro et al., 1993). Total nitrogen (TN) and total organic carbon (TOC) were measured in accordance with the method of Yeomans and Bremner (1988). Ammonia-N was determined by the indophenol blue photometric method based on Berthelot's reaction (Sommer et al. 1992). Nitrate-N was determined by ion chromatography (WIC-II ion chromatographer, Shanghai Cany Precision Instrument Co., Ltd., China) in a 1:20 (w/v) water extract. Humic acid (HA) and fulvic acid (FA) fractionations were determined according to Ciavatta et al. (1990).

OM loss was calculated from the initial $\left(\mathrm{X}_{1}\right)$ and final $\left(\mathrm{X}_{2}\right)$ ashes contents according to Equation (1) (Paredes et al., 2000):

OM loss $(\%)=100-100\left[\mathrm{X}_{1}\left(100-\mathrm{X}_{2}\right)\right] /\left[\mathrm{X}_{2}\left(100-\mathrm{X}_{1}\right)\right]$

Germination index (GI) was obtained by growing the seeds of Lepidium sativum L. (Zucconi et al., 1981) in a 1:2 (w/v) of the water-soluble extract of the compost. The extract was achieved by centrifuge the mixture (compost + distilled water) at 3200 rpm $(1147 \times \mathrm{g})$ for $30 \mathrm{~min}$, and then filtration through filter paper. The resultant solution was mixed with distilled water in the proportion of $100 \%, 75 \%$ and $50 \%$, 
respectively with $100 \%$ of distilled water as control in the experiment. Two $\mathrm{ml}$ of the mixture was added into a petri dish $(9 \mathrm{~cm})$ with filter paper laid previously, and 10 seeds of garden cress (Lepidium sativum L.) were spread on the filter paper. Then all the petri dishes were placed in an incubator at temperature of $25 \pm 1^{\circ} \mathrm{C}$ for $72 \mathrm{~h}$. The number of germinated seeds and root length were measured, and the GI was calculated according to Equation (2):

$\mathrm{GI}(\%)=100\left[\left(\mathrm{G}_{100 \%} \times \mathrm{R}_{100 \%}\right)+\left(\mathrm{G}_{75 \%} \times \mathrm{R}_{75 \%}\right)+\left(\mathrm{G}_{50 \%} \times \mathrm{R}_{50 \%}\right)\right] /\left(\mathrm{G}_{0 \%} \times \mathrm{R}_{0 \%} \times 3\right)$

where $\mathrm{G}_{100 \%}, \mathrm{G}_{75 \%}, \mathrm{G}_{50 \%}$ and $\mathrm{R}_{100 \%}, \mathrm{R}_{75 \%}, \mathrm{R}_{50 \%}$ were the numbers of germinated seeds and the average root lengths of designed treatments (100\%, $75 \%$ and $50 \%$ of compost extracts) respectively, $\mathrm{G}_{0 \%}$ and $\mathrm{R}_{0 \%}$ were the number of germinated seeds and the average root length of the control (100\% of distilled water).

Plant growth index (PGI) determination was conducted on the mixture of compost and peat at different ratios of $0 \%, 20 \%, 40 \%, 60 \%, 80 \%$ and $100 \%(\mathrm{v} / \mathrm{v})$. Plastic pots with volume of $1000 \mathrm{ml}$ were used to hold the mixtures and 125 seeds of garden cress (Lepidium sativum L.) were spread on the surface and covered with small amount of peat. The pots were placed in a climate chamber at temperature of $25 \pm 1^{\circ} \mathrm{C}$, humidity of $75 \pm 5 \%$ and $12 / 12$ of light/dark cycle and incubated for 3 weeks. The pots were irrigated with de-ionized water at a same interval determined previously. On the day of termination the seedlings were cut close to the substrate surface, dried $\left(105^{\circ} \mathrm{C}\right)$ and weighed. The PGI was expressed by the ratio of average weight of the treatments (20\%, $40 \%, 60 \%, 80 \%$ and $100 \%$ of compost) to the weight of the control samples $(0 \%$ of compost). 
The Solvita maturity index was also used and tested by following the guide to Solvita testing for compost maturity index (Woods End Research, 2002).

\subsection{Data analysis and statistics}

The first-order kinetic model, Equation (3), was adopted for OM degradation during the composting process in this study (Bernal et al., 1996; Bustamante et al., 2008). And the related kinetics calculation was completed by using the SPSS 17.0 and ORIGIN 8.0 computer program.

$$
\text { OM loss (\%) = A }\left(1-\mathrm{e}^{-\mathrm{kt}}\right)
$$

where $A$ is the maximum degradation of OM (\%), $k$ the rate constant $\left(\mathrm{d}^{-1}\right)$ and $t$ the composting duration (d). The residual mean square (RMS) was calculated to indicate the kinetic model fitting to the experimental results.

The results presented in this study were mean values \pm standard deviations.

Bivariable square Pearson's correlation analysis was applied to disclose the relationship between different maturity parameters. Significance was assumed if the $p$ $<0.05$.

\section{Results and discussion}

\subsection{Composting characteristics}

\subsubsection{Changes of temperature, $\mathrm{pH}$, and moisture}

In both piles, the temperature reached the thermophilic phase $\left(\max . \mathrm{T}=69.8{ }^{\circ} \mathrm{C}\right.$ in SM-RS pile and max. $\mathrm{T}=65.7{ }^{\circ} \mathrm{C}$ in DM-RS pile, respectively) within 2 days, and 
fell to the ambient temperature in about 60 days (Fig. 1). Four obvious temperature peaks can be observed in SM-RS pile, while only 3 peaks in DM-RS pile. The temperature drop between peaks may be attributable to the large amount of heat loss caused by manually mixing, and some time interval was needed for heat accumulation to reach the subsequent peak. This observation is to some extent in agreement with the reports by de Guardia et al. (2010a), Lee et al. (2002), and Himanen and Hänninen (2011) with slight difference in the duration of thermophilic phase and in the maximum temperature. Bernal et al. (2009) claimed that $40-65^{\circ} \mathrm{C}$ was the optimum temperature for composting and $>55^{\circ} \mathrm{C}$ was necessary to eliminate pathogenic microorganisms. In the study, both piles maintained between this temperature ranges for $4-5$ weeks, during which $>55{ }^{\circ} \mathrm{C}$ lasted for about 2 weeks. It can also be found that SM-RS pile reached the thermophilic phase quickly and had a longer duration of thermophilic phase than DM-SR pile (Fig. 1). This observation may be brought about by the different labile nature of carbon in these two animal manures and their thermal inertia (Bustamante et al., 2008). Besides, DM contains more cellulose, hemicelluloses, and lignin, resulting in more resistance to microbial attack than SM (Chen et al., 2003).

The initial pH values in SM-RS and DM-RS piles (6.25 and 6.30 respectively; Fig. 2a) are within the desirable range of 6 - 8 for composting (Bustamante et al., 2008; Troy et al., 2012), and the rapid increase in the initial 15 days could be attributed to the degradation of acid-type compounds and the mineralization of proteins, amino acids and peptides to ammonia. Then the $\mathrm{pH}$ values tended to be stable at 7.50-8.50 
and the peaks were detected at 8.33 on day 30 for SM-RS pile and at 7.98 on day 15 for DM-RS pile, reflecting high ammonia production. The final $\mathrm{pH}$ values decreased to 7.80 and 7.70 in SM-RS and DM-RS piles, respectively, possibly due to microbial nitrification (Nolan et al., 2011). The $\mathrm{pH}$ variation profiles in both piles are similar to Zhu (2007) and Li et al. (2008) who did co-composting of animal manure and rice straw.

In addition, the moisture contents decreased gradually in both piles, from the initial 51.04\% and 62.51\% to final $20.58 \%$ and $40.52 \%$ in SM-SR and DM-SR, respectively (Fig. 2b).

\subsubsection{Changes of TOC and OM}

TOC and OM were detected to decrease gradually during the composting process in both piles. The initial TOCs, $42.21 \%$ and $42.67 \%$, decreased to $35.65 \%$ and $37.63 \%$ in the final composts of SM-RS and DM-RS piles, respectively (Fig. 2c).

Correspondingly, the OM contents gradually decreased from initial values of $72.77 \%$ and $73.48 \%$ to final values of $61.45 \%$ and $64.87 \%$ in the SM-RS and DM-RS piles, respectively (Fig. 2c). Compared with DM-RS, SM-RS feedstock exhibited a slightly faster decomposition based on TOC and OM reduction, probably attributing to more easily degradable organics contained in SM than in DM (Chen et al., 2003).

The OM degradation followed the first-order kinetic model (Equation (3)) in both piles, and the following parameters were obtained from the curve fitting to the experimental data:

SM-RS pile: $A=69.37 \pm 5.54, k=0.00985 \pm 0.00112 d^{-1}, R M S=0.9982(p<0.001)$ 
DM-RS pile: $A=65.19 \pm 18.86, k=0.00831 \pm 0.00324 d^{-1}, R M S=0.9849(p<0.001)$

The $A$ values obtained in this study are within the range of 55\%-72.5\% obtained by Paredes et al. (2000; 2001) and Bustamante et al. (2008). The OM decomposition in SM-RS pile was slightly faster than that in DM-RS pile, indicated by its higher $k$, which is in agreement with the above mentioned TOC changes in the two piles (Fig. 2c).

\subsubsection{Changes of different forms of nitrogen}

The changes of TN, ammonia-N and nitrate-N are illustrated in Fig. 2d and Fig. 2e, respectively. A more rapid increase in TN was observed in the initial stage in SM-RS pile, possibly due to its lower $\mathrm{C} / \mathrm{N}$ ratio thus higher $\mathrm{N}$ content during the composting process. In contrast with the relatively stable nitrate-N levels in both piles, ammonia-N remained stable till day 60 and then decreased greatly in SM-SR pile, while in DM-SR pile the ammonia-N increased to almost the same level as in SM-RS pile on day 60 and then decreased to its initial level in the final compost. This phenomenon may be closely associated with the activity and community evolution of the inhabited ammonification and nitrifying bacteria in the piles, and high temperature and volatilization may add some contribution to the loss of ammonia- $\mathrm{N}$ in the composts (Bustamante et al., 2008; Huang et al., 2004). Much less changes in nitrate-N was observed during the composting, implying less risk of nitrate contamination of the groundwater when the compost being applied in land (Bernal et al., 2009).

\subsubsection{Change of Humus}


The HA content fluctuated during the composting process and the FA seemed to change in an opposite pattern with HA in both piles (Fig. 2f), reflecting the humification of OM. This observation doesn't agree with the previous studies (Ko et al., 2008; Paredes et al., 2000) in which obvious trends of increase in HA and decrease in FA were noticed, probably attributable to the different origin and nature of the feedstocks used in this study.

\subsection{Maturity evaluation}

\subsubsection{Changes of GI and PGI}

The parameters of GI and PGI can be used to indicate the phytotoxicity of composts to plants. Table 2 shows that the GI and PGI values increased with the progress of composting in both piles, and reached greater than $100 \%$ for GI and above 1.00 for PGI after $90 \mathrm{~d}$, signaling no phytotoxicity problem in the final compost (Zucconi et al., 1981; Himanen and Hänninen, 2011). Compared to DM-RS, SM-RS showed higher PGI values with GI faster increasing, indicating a more speedy process of maturation during the co-composting with rice straw.

\subsubsection{Changes of $C / N, H A / F A$, and Solvita maturity index}

The $\mathrm{C} / \mathrm{N}$ ratio decreased faster in SM-RS pile than in DM-RS pile, especially during the first 30 days of the composting process. The $\mathrm{C} / \mathrm{N}$ ratios in both piles almost reached $<25$ after 60 days' composting, higher than the results $(\mathrm{C} / \mathrm{N}=9-17)$ obtained by Huang et al. (2004) possibly due to much higher initial C/N ratios ( 35- 40) of the feedstocks used in both piles.

From Table 2, it can be seen that the ratio of HA to FA(HA/FA), i.e. degree of 
polymerization, in both piles didn’t clearly display a classic increase trend throughout the composting process observed by Bernal et al. (2009) and He et al. (2013). However, this observation is similar with the results from the co-composting of cattle/poultry manure with distillery wastes by Bustamante et al. (2008) and the co-composting of poultry manure with sawdust by Dias et al.(2010), partly attributed to the different origin of raw materials.

Although no clear trend was found in HA/FA ratio in this study, the gradual increase of Solvita maturity index till the end of composting in both piles signals the maturation process in these two piles. Based on Solvita maturity index, the compost maturity of the two piles can be comparable to the commercial products after 90 days' composting (Table 2).

\subsubsection{Maturity evaluation index system}

Many parameters have been used to indicate the maturation process of composting and included in the maturity parameters systems (Grube et al., 2006; Ko et al., 2008; Gómez-Brandón et al., 2008). In this study, the Solvita maturity index, a widely recognized and obtained by simple tests, is taken as a standard index. Table 3 lists the bivariable square Pearson's correlation coefficients between Solvita matutiry index and some commonly used maturity parameters. Clearly, except HA/FA ratio, the other maturity parameters such as C/N ratio, GI and PGI are significantly correlated with the Solvita maturity index. Therefore, the $\mathrm{C} / \mathrm{N}$ ratio, GI and PGI can be included into the maturity evaluation index system in order to assess the compost maturity effectively. The negative coefficients between $\mathrm{C} / \mathrm{N}$ ratio and other maturity 
parameters (including Solvita index, GI and PGI) denote the decrease trend of C/N ratio during the maturation process. Both GI and PGI can be used as the indicators of compost phytotoxicity. GI test is a quick method for evaluating phytotoxicity within a short period, while PGI test can give a better estimation of compost impact on plant growth for a longer time, thus the application of GI or PGI test can be determined from practical needs and on time requirement.

According to the maturity tests on the products from SM-RS pile, DM-RS pile and the two commercial composts, a suitable $\mathrm{C} / \mathrm{N}$ ratio is difficult to define due to different carbon and nitrogen sources (thus different $\mathrm{C} / \mathrm{N}$ ratio) in the feedstocks. In this study, however, suitable values of GI and PGI could be proposed for composting products from the tests of livestock manure and rice straw, greater than $120 \%$ and 1.00 , respectively.

\section{Conclusions}

The present study indicates that mature compost could be achieved after 90 days' co-composting of livestock manure and rice straw, in which SM-RS exhibits slightly faster maturation due to a relatively longer thermophilic phase, higher OM degradation rate, GI and PGI. Our findings also suggest that a comprehensive maturity evaluation index system consisting of chemical (C/N ratio) and biological (GI or PGI) parameters is much more suitable and practical for the maturity assessment of compost. The suitable values of GI and PGI are proposed as greater than $120 \%$ and 1.00 , respectively for mature compost. 


\section{Acknowledgements}

The work was supported by the Sino-Italian Cooperation Program for

Environmental Protection. The authors would like to thank Ms. Maria Lodovia

Gullino and Mr. Massimo Pugliese (from Turin University of Italy) and Mr. Giovanni

Minuto (from the Regional Center for Agricultural Experimentation and Assistance of Savona of Italy) for their technical guidance in carrying out the experiments.

\section{References}

Bernal, M.P., Navarro, A.F., Roig, A., Cegarra, J., García, D., 1996. Carbon and nitrogen transformation during composting of sweet sorghum bagasse. Biol. Fert. Soils 22, 141-148.

Bernal, M.P., Alburquerque, J.A., Moral, R., 2009. Composting of animal manures and chemical criteria for compost maturity assessment. A review. Bioresour. Technol. 100, 5444-5453.

Bustamante, M.A., Paredes, C., Marhuenda-Egea, F.C., Pérez-Espinosa, A., Bernal, M.P., Moral, R., 2008. Co-composting of distillery wastes with animal manures: Carbon and nitrogen transformations in the evaluation of compost stability. Chemosphere 72, 551-557.

Chen, S., Liao, W., Liu, C., Wen, Z., Kincaid, R.L., Harrison, J.H., Elliott, D.C., Brown, M.D., Solana, A.E., Stevens, D.J., 2003. Value-Added Chemicals from Animal Manure - Final Technical Report, Northwest Bioproducts Research Institute, Richland, WA, 9-10. 
Ciavatta, G., Govi, M., Vittori Antisari, L., Sequi, P., 1990. Characterization of humified compounds by extraction and fractionation on solid polyvinyl polypyrrolidone. J. Chomatogr. A 509, 141-146.

de Guardia, A., Mallard, P., Teglia, C., Marin, A., Le Pape, C., Launay, M., Benoist J.C., Petiot, C., 2010a. Comparison of five organic wastes regarding their behaviour during composting: Part 1, biodegradability, stabilization kinetics and temperature rise. Waste Manage. 30, 402-414.

de Guardia, A., Mallard, P., Teglia, C., Marin, A., Le Pape, C., Launay, M., Benoist J.C., Petiot, C., 2010b. Comparison of five organic wastes regarding their behaviour during composting: Part 2, nitrogen dynamic. Waste Manage. 30, 415-425.

Dias, B.O., Silva, C.A., Higashikawa, F.S., Roig A., Sánchez-Monedero M.A., 2010. Use of biochar as bulking agent for the composting of poultry manure: Effect on organic matter degradation and humification. Bioresour. Technol. 101, 1239-1246.

Gao, M.C., Liang, F.Y., Yu, A., Li, B., Yang, L.J., 2010. Evaluation of stability and maturity during forced-aeration composting of chicken manure and sawdust at different $\mathrm{C} / \mathrm{N}$ ratios. Chemosphere 78, 614-619.

Grube, M., Lin, J.G., Lee, P.H., Kokorevicha, S., 2006. Evaluation of sewage sludge-based compost by FT-IR spectroscopy. Geoderma 130, 324-333.

Gómez-Brandón, M., Lazcano, C., Domínguez, J., 2008. The evaluation of stability and maturity during the composting of cattle manure. Chemosphere 70, 436-444. 
He, M.M, Li, W.H., Liang, X.Q., Wu, D.L., Tian, G.M., 2009. Effect of composting process on phytotoxicity and speciation of copper, zinc and lead in sewage sludge and swine manure. Waste Manage. 29, 590-597.

He, X.S., Xi, B.D., Jiang, Y.H., He, L.S., Li, D., Pan, H.W., Bai, S.G., 2013. Structural transformation study of water-extractable organic matter during the industrial composting of cattle manure. Microchem. J. 106, 160-166.

Himanen M., Hänninen M., 2011. Composting of bio-waste, aerobic and anaerobic sludges - Effect of feedstock on the process and quality of compost. Bioresour. Technol. 102, 2842-2852.

Hu, Z.H., Liu, Y.L., Chen, G.W., Gui, X.Y., Chen, T.H., Zhan, X.M., 2011. Characterization of organic matter degradation during composting of manure-straw mixtures spiked with tetracyclines. Bioresour. Technol. 102, 7329-7334.

Huang, G.F., Wong, J.W.C., Wu, Q.T., Nagar, B.B., 2004. Effect of C/N on composting of pig manure with sawdust. Waste Manage. 24, 805-813.

Ko, H.J., Kim, K.Y., Kim, H.T., Kim, C.N., Umeda, M., 2008. Evaluation of maturity parameters and heavy metal contents in composts made from animal manure. Waste Manage. 28, 813-820.

Lee, I.B., Kim, P.J., Chang, K.W., 2002. Evaluation of stability of compost prepared with Korean food waste. Soil Sci. Plant Nutr. 48 (1), 1-8.

Li X.J., Zhang R.H., Pang Y.Z., 2008. Characteristics of dairy manure composting with rice straw Bioresour. Technol. 99, 359-367. 
NBSC (National Bureau of Statistics of China), 2011. China Statistical Yearbook. China Statistics Press, Beijing.

Nolan, T., Troy, S. M., Healy, M. G., Kwapinski, W., Leahy J. J., Lawlor P. G., 2011. Characterization of compost produced from separated pig manure and a variety of bulking agents at low initial C/N ratios. Bioresour. Technol. 102, 7131-7138.

Navarro, A.F., Cegarra, J., Roig, A., García, D., 1993. Relationships between organic matter and carbon contents of organic wastes. Bioresource Technol. 44, 203-207.

Paredes, C., Bernal, M.P., Roig, A., Cegarra, J., 2001. Effects of olive mill wastewater addition in composting of agroindustrial and urban wastes. Biodegradation 12, 225-234.

Paredes, C., Roig, A., Bernal, M.P., Sánchez-Monedero, M.A., Cegarra, J., 2000. Evolution of organic matter and nitrogen during co-composting of olive mill wastewater with solid organic wastes. Biol. Fert. Soils 32, 222-227.

Sommer S.G., Kjellerup V., Kristjansen O., 1992. Determination of total ammonium nitrogen in pig and cattle slurry: sample preparation and analysis. Acta Agric. Scand. Section B 42, 146-151.

Tomati, U., Madejón, E., Galli, E., 2000. Evolution of humic acid molecular weight as an index of compost stability. Compost Sci. Util. 8, 108-115.

Troy, S.M., Nolan, T., Kwapinski, W., Leahy, J.J., Healy, M.G., 2012. Effect of sawdust addition on composting of separated raw and anaerobically digested pig manure. J. Environ. Manage. 111, 70-77.

Wang, H., Qin, Y., Yu, K., 2008. Utilization, distribution and exploitation tactics of 
crop stalk resources in China. Territory and Natural Resources Study 2, 92-93 (in Chinese).

Woods End Research, 2002. Guide to Solvita testing for compost maturity index. Compost New Manual 11, 1-8.

Yeomans, J.C., Bremner, J.M., 1988. A rapid and precise method for routine determination of organic carbon in soil. Commun. Soil Sci. Plant Analyst 19, 1467-1476.

Zhu, N., 2007. Effect of low initial C/N ratio on aerobic composting of swine manure with rice straw. Bioresour. Technol. 98, 9-13.

Zucconi, F., Pera, A., Forte, M., de Bertoldi, M., 1981. Evaluating toxicity of immature compost. BioCycle 22, 54-57. 


\section{Tables}

Table 1

Main characteristics of the three feedstocks and two commercial compost products used in this study (dry weight).

\begin{tabular}{llllll}
\hline Parameters & Rice straws & $\begin{array}{l}\text { Swine } \\
\text { manure }\end{array}$ & $\begin{array}{l}\text { Dairy } \\
\text { manure }\end{array}$ & $\begin{array}{l}\text { Commercial } \\
\text { compost A }\end{array}$ & $\begin{array}{l}\text { Commercial } \\
\text { compost B }\end{array}$ \\
\hline Moisture (\%) & $11.07 \pm 1.00$ & $81.95 \pm 0.56$ & $84.25 \pm 0.69$ & $27.08 \pm 0.86$ & $37.41 \pm 1.09$ \\
Total organic carbon (TOC, \%, d.w.) & $38.73 \pm 0.99$ & $42.20 \pm 0.45$ & $41.10 \pm 1.22$ & $36.19 \pm 1.13$ & $36.47 \pm 0.95$ \\
Total nitrogen (TN, \%, d.w.) & $0.54 \pm 0.07$ & $3.17 \pm 0.07$ & $2.61 \pm 0.13$ & $1.63 \pm 0.05$ & $1.64 \pm 0.12$ \\
C/N ratio (TOC/TN) a & 71.72 & 13.31 & 15.75 & 22.20 & 22.24 \\
Total phosphorus (TP, \%, d.w.) & $0.09 \pm 0.02$ & $1.28 \pm 0.13$ & $0.65 \pm 0.06$ & $2.09 \pm 0.15$ & $2.14 \pm 0.27$ \\
pH & N.D. & $7.64 \pm 0.43$ & $8.03 \pm 0.58$ & $7.45 \pm 0.03$ & $7.50 \pm 0.06$ \\
\hline
\end{tabular}

The data are indicated by mean \pm standard deviation for triplicate determinations. N.D., no determination.

${ }^{a}$ Average value of the triplicate determinations. 
Table 2

Changes of principal maturity parameters during composting of livestock manure and rice straw

\begin{tabular}{|c|c|c|c|c|c|}
\hline $\begin{array}{l}\text { Composting } \\
\text { time (days) }\end{array}$ & $\mathrm{C} / \mathrm{N}$ & HA/FA & Solvita maturity index & GI & PGI \\
\hline \multicolumn{6}{|c|}{ SM-RS pile: swine manure + rice straws } \\
\hline 0 & 42.21 & 1.67 & N.D. & N.D. & N.D. \\
\hline 30 & 28.57 & 1.02 & 5 & $68 \%$ & 1.03 \\
\hline 60 & 24.86 & 1.68 & 6 & $86 \%$ & 1.04 \\
\hline 90 & 22.92 & 1.22 & 8 & $129 \%$ & 1.12 \\
\hline
\end{tabular}

DM-RS pile: dairy manure + rice straws

\begin{tabular}{|c|c|c|c|c|c|}
\hline 0 & 40.21 & 1.05 & N.D. & N.D. & N.D. \\
\hline 30 & 35.44 & 0.74 & 5 & $88 \%$ & 0.81 \\
\hline 60 & 27.59 & 1.02 & 7 & $96 \%$ & 0.93 \\
\hline 90 & 24.95 & 1.28 & 8 & $119 \%$ & 1.01 \\
\hline
\end{tabular}

Commercial compost A: swine manure + rice straws
70
22.20
N.D.
8
$145 \%$
1.09

Commercial compost B: dairy manure + rice straws

$\begin{array}{llllll}75 & 22.24 & \text { N.D. } & 8 & 126 \% & 1.02\end{array}$

$C / N$, ratio of total organic carbon to total nitrogen; HA/FA, ratio of humic acid to fulvic acid; GI, germination index; PGI, plant growth index. N.D., no determination. 
Table 3

Coefficients between Solvita index and some commonly used maturity parameters through bivariable square Pearson's correlation analysis

\begin{tabular}{|c|c|c|c|c|c|}
\hline Parameters & Solvita maturity index & $\mathrm{C} / \mathrm{N}$ & HA/FA & GI & PGI \\
\hline \multicolumn{6}{|c|}{ SM-RS pile: swine manure + rice straws } \\
\hline Solvita index & 1 & $-0.987 * *$ & 0.471 & $.912 *$ & $0.818^{*}$ \\
\hline $\mathrm{C} / \mathrm{N}$ & $-1.000 * *$ & 1 & -0.461 & $-.917 *$ & $-0.825 *$ \\
\hline HA/FA & 0.471 & -0.461 & 1 & .068 & -0.122 \\
\hline GI & $0.912 *$ & $-0.917 *$ & 0.068 & 1 & $0.982 * *$ \\
\hline PGI & $0.818^{*}$ & $-0.825^{*}$ & -0.122 & $0.982 * *$ & 1 \\
\hline \multicolumn{6}{|c|}{ DM-RS pile: dairy manure + rice straws } \\
\hline Solvita index & 1 & $-0.961 * *$ & 0.865 & $0.963 *$ & $0.993 * *$ \\
\hline $\mathrm{C} / \mathrm{N}$ & $-0.961 * *$ & 1 & -0.967 & -0.852 & $-0.987 * *$ \\
\hline $\mathrm{HA} / \mathrm{FA}$ & 0.865 & -0.767 & 1 & 0.957 & $0.996 * *$ \\
\hline GI & $0.963 *$ & -0.852 & 0.957 & 1 & $0.926^{*}$ \\
\hline PGI & $0.993^{* *}$ & $-0.987 * *$ & $0.996 * *$ & $0.926 *$ & 1 \\
\hline
\end{tabular}

$C / N$, ratio of total organic carbon to total nitrogen; HA/FA, ratio of humic acid to fulvic acid; GI, germination index; PGI, plant growth index. ${ }^{*} p<0.05 ;{ }^{* *} p<0.01$. 
Figure captions:

2

3 Fig. 1. Changes of temperature during co-composting of livestock manure and rice

4 straw

5 Fig. 2. Changes of principal physico-chemical properties during composting of

6 livestock manure and rice straws. (a) $\mathrm{pH}$; (b)Moisture; (c) total organic carbon (TOC)

7 and organic matter (OM); (d) total nitrogen (TN); (e) ammonia nitrogen (Ammonia-N)

8 and nitrate nitrogen (Nitrate-N); (f) humic acid (HA) and fulvic acid (FA).

$9 \quad$ Fig. 3. Organic matter $(\mathrm{OM})$ losses during composting of SM-RS and DM-RS (lines represent curve-fitting). 


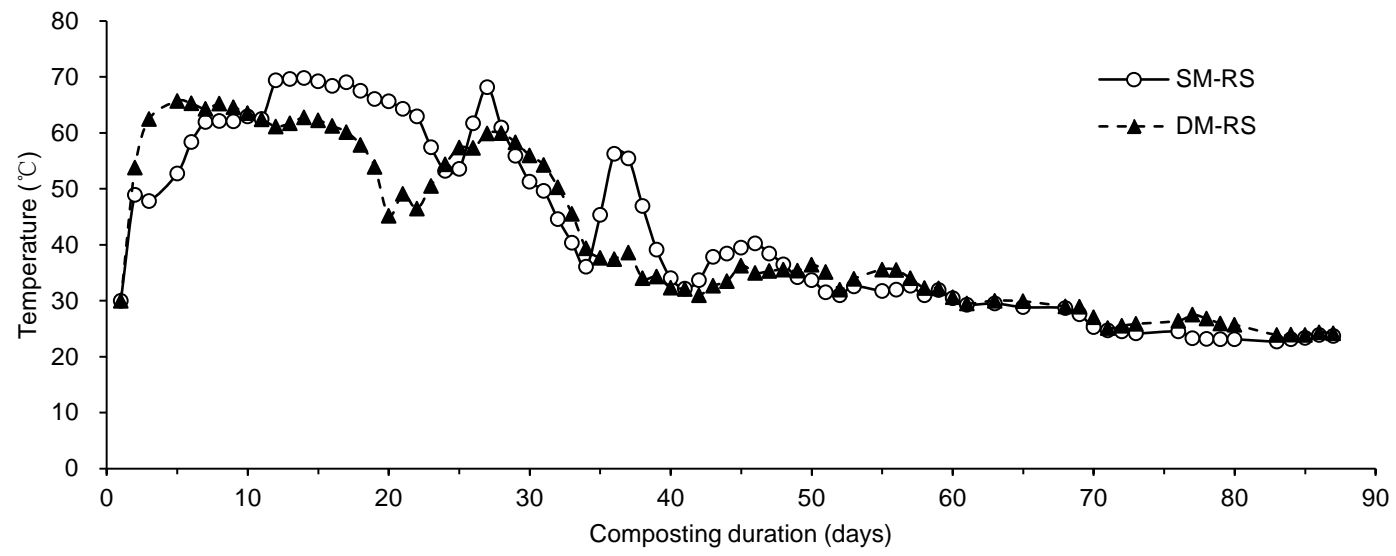

2

3

4

Fig. 1. Qian et al. 

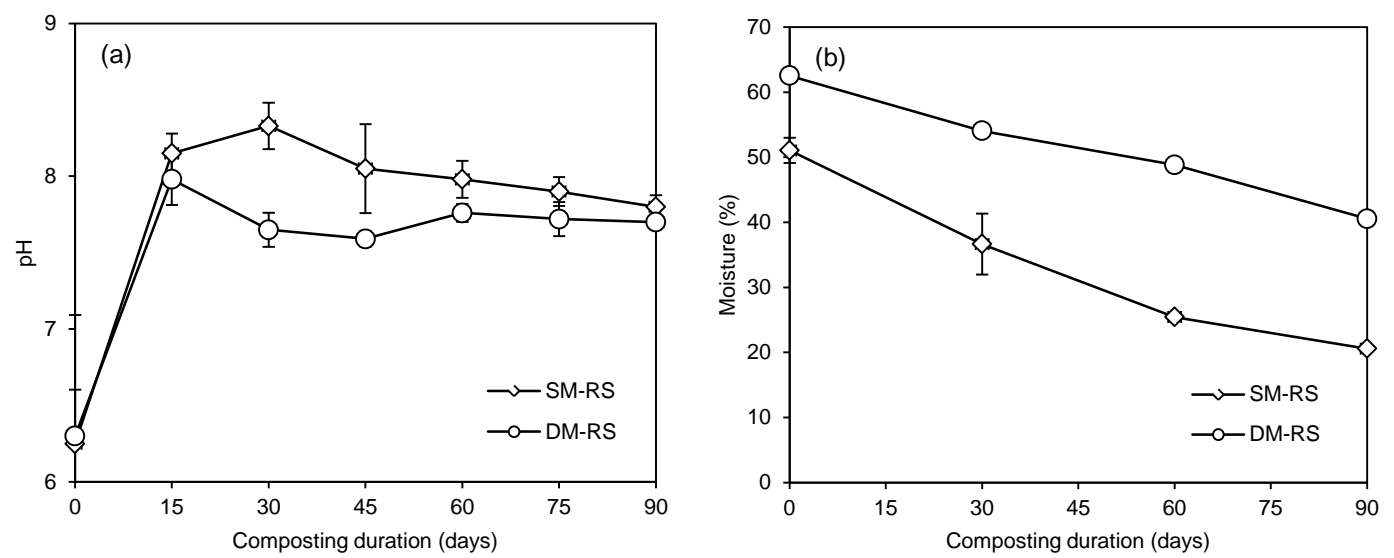

2
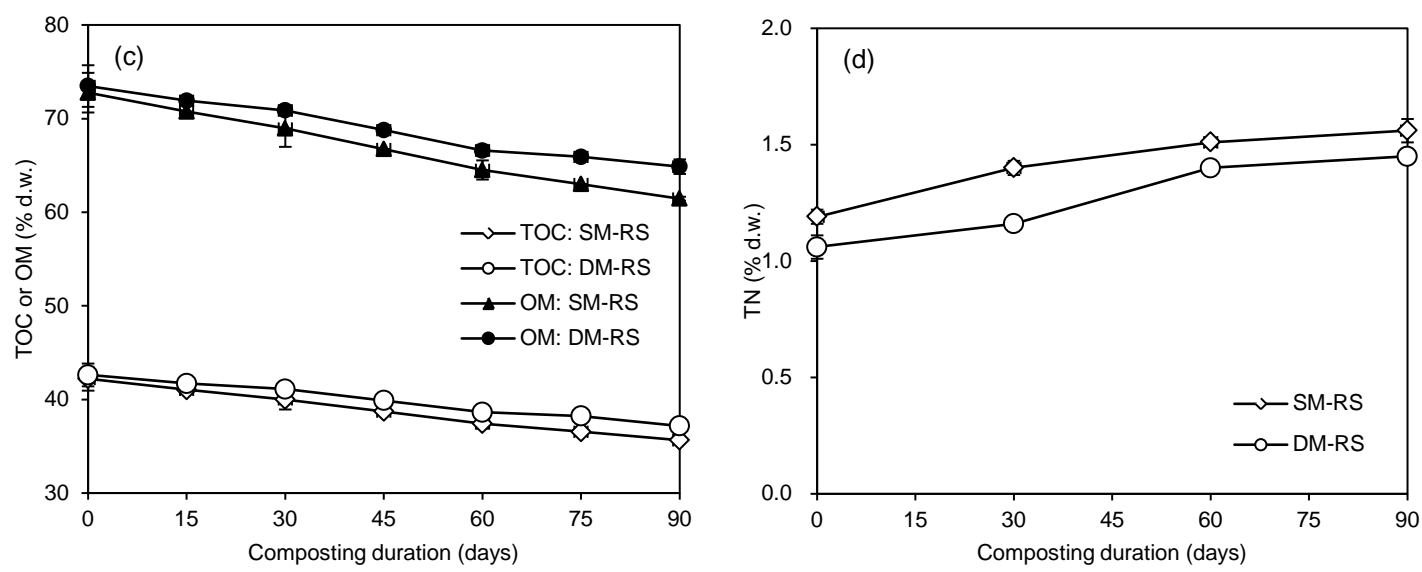

3
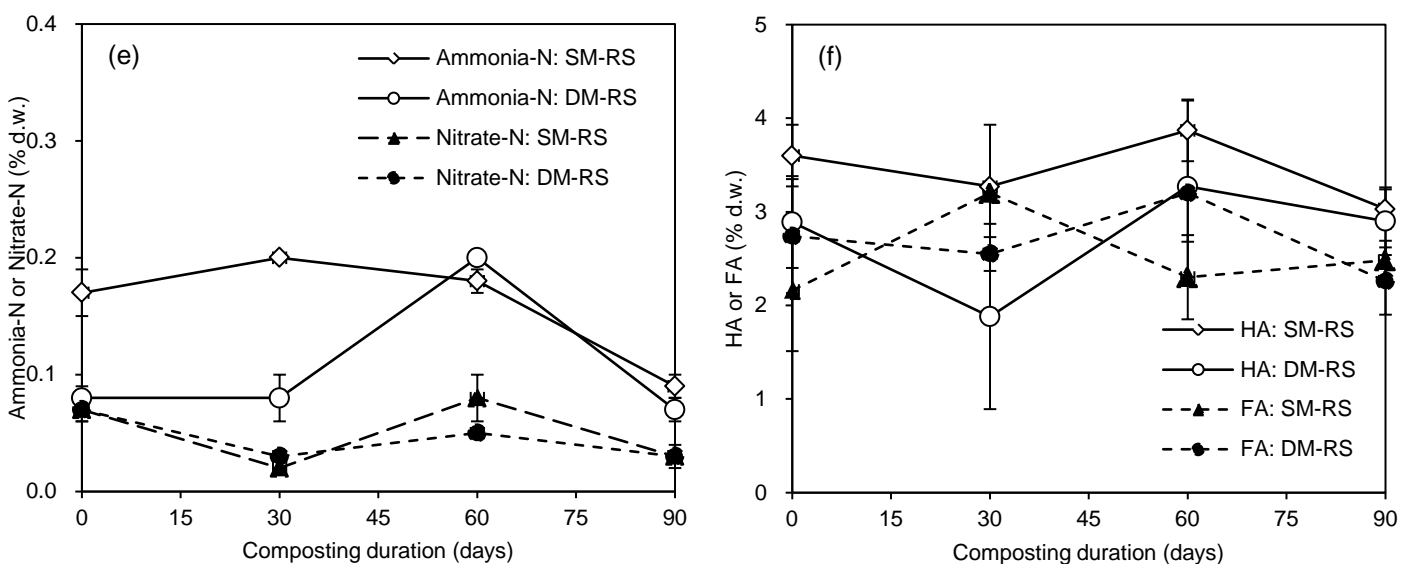

4

Fig. 2. Qian et al. 


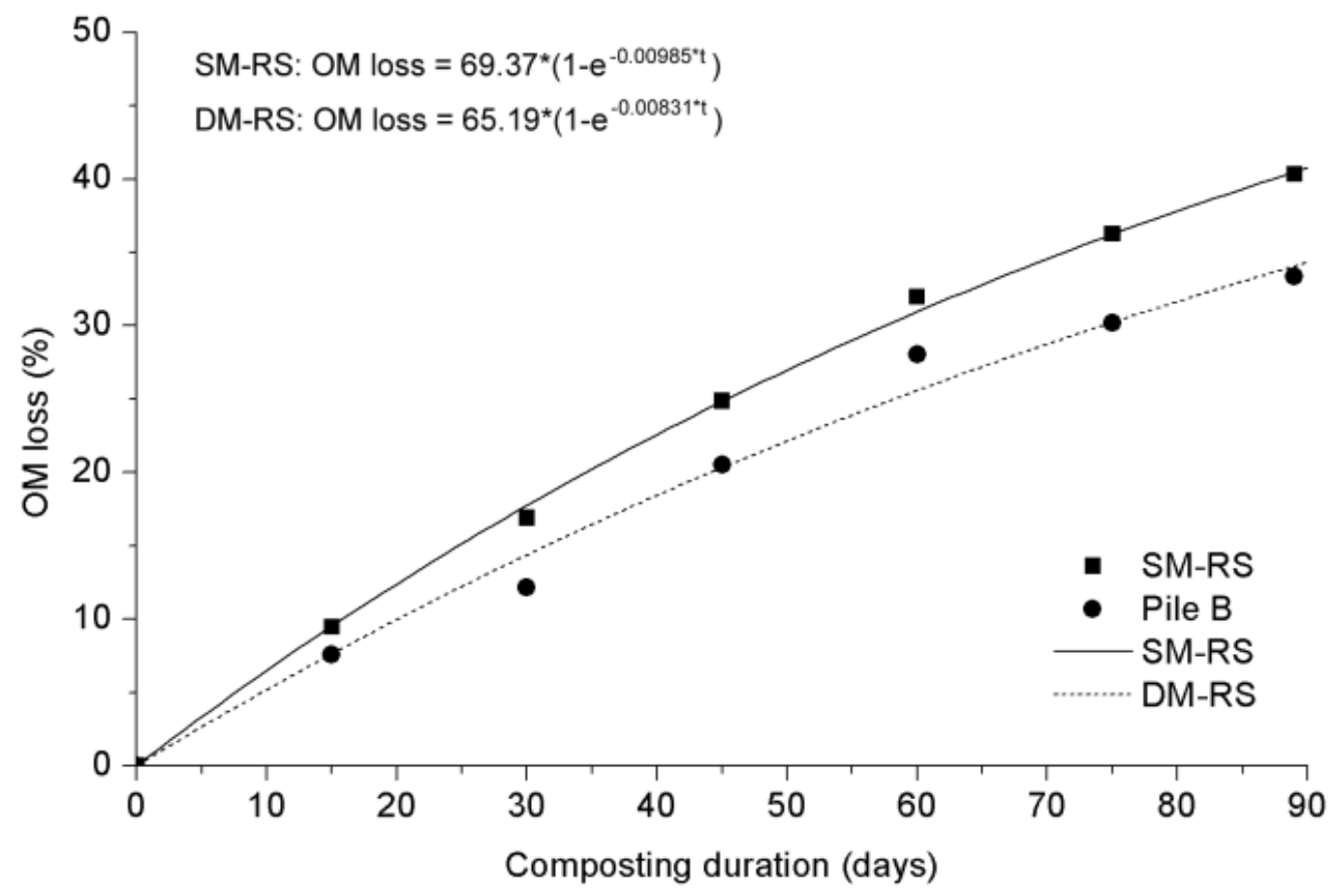

1

Fig. 3. Qian et al.

4 